\title{
COMPARISON OF HEALTH LITERACY AMONG IRAQI WOMEN WITH DIFFERENT AGE GROUPS
}

\author{
ZENA MUDHAFER AL-NEMA*
}

Department of Clinical Pharmacy, College of Pharmacy, University of Baghdad, Baghdad, Iraq. *Email: zena_alnema@yahoo.com

\author{
Received: 21 September 2017, Revised and Accepted: 30 October 2017
}

\section{ABSTRACT}

Objectives: The objectives of the study were to compare the health knowledge of women of different age groups. To evaluate different methods for developing health literacy.

Methods: A cross-sectional study was conducted from December 2014 to January 2016 in Baghdad, Iraq. All candidates were females, age $\geq 18$ years, neither medical staff nor medical students.

The sample was divided into two groups: Group A: Females aged18-45 years, Group B: Females aged >45 years. A comparison between the two groups regarding their health literacy and the source of information was made.

Results: The final sample included 213 women, of them, there were $107 \leq 45$ years (Group A) and $106>45$ years (Group B) women. Significant difference was found between both groups regarding the knowledge about the prevention of cholera where the accurate answers were $46.7 \%$ in Group A versus $80.1 \%$ in Group B. The main source of information for both groups was the personal experience. However, internet was used more $(42 \%)$ by the younger women (Group A), and television was used more (52.8\%) by the older women (Group B).

Conclusion: Young women had a better literacy on common medical problems, but the old showed overall limited health literacy. Pharmacists, physicians, and activities of the Ministry of Health played an impotent role in health literacy in the old women.

Keywords: Women's health literacy, Information sources, Medical staff

(c) 2018 The Authors. Published by Innovare Academic Sciences Pvt Ltd. This is an open access article under the CC BY license (http://creativecommons. org/licenses/by/4. 0/) DOI: http://dx.doi.org/10.22159/ajpcr.2018.v11i2.22707

\section{INTRODUCTION}

The WHO definition of health education is "any combination of learning experiences designed to help individuals and communities improve their health, by increasing their knowledge or influencing their attitudes" [1]

Health literacy is an effective way used by the health authorities to develop the health system because it was found inexpensive; and remains the only method for generating the enabling environment for health to develop [2].

For adult people, it was found that there is a direct relationship between low health literacy and a poor understanding of preventive information and access to preventive services [3].

Studies suggest that health professionals have a limited understanding of health literacy and the consequences of low health literacy for their patients. This will limit health professionals' ability to improve their patients' health literacy skills and thus will limit patients' ability to improve understanding their illness and instructions to manage their health conditions [4].

Developing health literacy means in addition to information transmission, also helping people to reach medical information and their ability to use it effectively, it is well known that developing health literacy is critical to empowerment. Emphasis is directed toward more personal forms of communication, and community-based educational help, as well as the political content of health literacy, focused on equipping people to resolve structural difficulties to health [5]

There are many methods to improve health literacy among the general population, of which the medical and pharmaceutical staff forms the cornerstone, but unfortunately, many studies reporting that not enough help was provided by pharmacy staff when handling self-medication needs even in developing countries [6].

These results open the door in front of us in the education of the general public by improving communication skills of pharmacists.

Regarding electronic literacy, many developed countries widely improved health literacy using this technology, on the other hand, many developing countries are trying very hard to develop their health care system into the information age. Millions of citizens in Africa do not have access to online sources and hence have poor individual health information [7].

The objective of the present study is to evaluate the effect of age of women on their knowledge with some basic medical issues and to evaluate different methods for developing health literacy. Thus, health authorities can make an effective use of the resources available to improve health literacy among Iraqi women and hence improving children's health

\section{METHODS}

A cross-sectional study was conducted from December 2014 to January 2016 in Baghdad city, capital of Iraq.

Sample was collected randomly from hospitals of the Medical City in Baghdad (non-medical staff), College of Pharmacy, school teachers, relatives, and clinics.

Inclusion criteria

Females, age $\geq 18$ years, neither medical staff nor medical students.

\section{Exclusion criteria}

Males of all ages, females $<18$, refuses to participate in the study, a medical staff or student. 
The sample was divided into two groups:

Group A: Females aged 18-45 years.

Group B: Females aged $>45$ years.

The candidates were interviewed by the researcher and certain points regarding the medical knowledge were interpreted, and the response of the candidates was recorded as follows:

- Accurate; if the response was similar or near to the medical truth.

Inaccurate; if it was different from the medical truth.

Don't know; if the candidate did not know the answer.

The medical information tested included the following:

1. Signs and symptoms of typhoid fever

2. Causes of typhoid fever.

3. Route of transmission of typhoid fever

4. Types of viral hepatitis.

5. Route of transmission of viral hepatitis.

6. Causes of cholera.

7. Prevention of cholera.

8. Route of transmission of cholera.

9. Route of transmission of polio.

10. Age of polio vaccination.

11. Are antibiotics effective for influenza or common cold?

12. Which is better a prescription containing one drug or another containing many drugs?

13. Source of information whether it is taken from parents, schools, media (TV, Broadcast, Net, and Newspapers), or activities of the health institutes.

These medical information was chosen believing that these health issues were among the most common medical problems facing the general population in Baghdad and might reflect the knowledge of other similar condition.

A comparison between the two groups regarding their health literacy was made. Measurement of the influence of health information was also evaluated. The results were tabulated, and statistical comparison was done between the two groups using Chi-square. $p<0.05$ was considered significant.

\section{RESULTS}

There were a total number of 213 women enrolled in this study. If there were 107 age 18-45 years (Group A) and 106>45 years old (Group B) women.

Comparison of both groups' medical knowledge: When we compare between the medical information owned by women in Group A with that of women in Group B, the most remarkable results of this comparison is the significant difference $(\mathrm{p}<0.0001)$ regarding ideas about the prevention of cholera where the accurate answers was $(46.7 \%)$ in young women versus $(80.1 \%)$ in old women. Another significant result was found in the knowledge about the route of transmission of viral hepatitis $(p=0.000038)$, correct answers were $(34.5 \%)$ in young women, and (51.8\%) in older women. Furthermore, there was a significant difference $(\mathrm{p}=0.009)$ when talking about the age of polio vaccination which accurate answers were $(41.1 \%)$ in young subjects versus $(56.6 \%)$ in older ones.

An exciting result was found when $90.6 \%$ of the young group and $72.6 \%$ of the old group answered correctly about the cause of cholera (Table 1). Meanwhile, the table showed a non-significant difference $(p=0.858)$ regarding the medical knowledge about the prescriptions weather containing one or many drugs where the accurate answers were $(67.2 \%$ vs. $75.4 \%)$ in the younger and older women, respectively.

On the other hand, when analyzing the source of medical information for both groups (Table 2), a significant difference was found in the health literacy gained through personal experience, pharmacist education, and television. It was also obvious that there was a nonsignificant difference in the health literacy gained by the subjects as a result of contact with physician education or gained through internet, radio and the activities of the Iraqi Ministry of Health (posters, lectures, meetings or conferences). Many of the women involved in this study had more than one source of information.

\section{DISCUSSION}

According to the answers to the 12-question - questionnaire in the study, it was found that women in Group A were more alert regarding routes of transmission of typhoid fever and cholera than women in Group B. On the other hand, women in Group B were more alert in routes of transmission of viral hepatitis, prevention of cholera, age of polio vaccination and the use of antibiotics for common cold and flu. This agrees with a study conducted by Barah and Gonçalves in Syria in 2010 who found that the young showed lower practice and knowledge about antibiotics and they concluded that hard educational work is required to reduce patient's need for antibiotics [8].

This study found that women in both groups depended mainly on personal experience as a source of information the television ranked second source of information for women in Group B whereas, those in Group A depended secondly on internet. Hence, the younger age group, used internet as a source of medical information more than older group, this agrees with results of a study done by Smith-Barbaro et al. in 2001 in Texas USA who found that a steady decline in the use of intended Web site was clear with advancing age [9], therefore,

Table 1: Comparison of both groups knowledge

\begin{tabular}{|c|c|c|c|c|c|}
\hline \multirow[t]{3}{*}{ Questions } & \multicolumn{4}{|c|}{ Number of subjects answered (\%) } & \multirow[t]{3}{*}{$\mathbf{p}$} \\
\hline & \multicolumn{2}{|c|}{$18-45$ years $(n=107)$} & \multicolumn{2}{|c|}{$>45$ years $(n=106)$} & \\
\hline & Accurate & Non accurate & Accurate & Non accurate & \\
\hline Signs and symptoms of typhoid fever & $63(58.8)$ & $44(41.1)$ & $55(51.8)$ & $46(43.3)$ & 0.519 \\
\hline Causes of typhoid fever & $33(30.8)$ & $74(69.1)$ & $38(35.8)$ & $59(55.6)$ & 0.212 \\
\hline Route of transmission of typhoid fever & $82(76.6)$ & $25(23.3)$ & $50(47.1)$ & $38(35.8)$ & $0.003^{*}$ \\
\hline Types of viral hepatitis & $48(44.8)$ & $16(14.9)$ & $24(22.6)$ & $17(16)$ & 0.076 \\
\hline Causes of cholera & $97(90.6)$ & $2(1.8)$ & $77(72.6)$ & $2(1.8)$ & 0.819 \\
\hline Prevention of cholera & $50(46.7)$ & $57(53.2)$ & $85(80.1)$ & $15(14.1)$ & $0.0001^{*}$ \\
\hline Route of transmission of cholera & $78(72.8)$ & $29(27.1)$ & $51(48.1)$ & $45(42.4)$ & $0.003^{*}$ \\
\hline Route of transmission of polio & $14(13)$ & $64(59.8)$ & $15(14.1)$ & $41(38.6)$ & 0.220 \\
\hline Age of polio vaccination & $44(41.1)$ & $61(57)$ & $60(56.6)$ & $40(37.7)$ & $0.009^{*}$ \\
\hline Are antibiotics effective for influenza or common cold? & $31(28.9)$ & $75(70)$ & $77(72.6)$ & $29(27.3)$ & $0.0^{*}$ \\
\hline $\begin{array}{l}\text { Which is better a prescription containing one drug or } \\
\text { another containing many drugs? }\end{array}$ & $72(67.2)$ & $22(20.5)$ & $80(75.4)$ & $23(21.6)$ & 0.858 \\
\hline
\end{tabular}

Values are presented as numbers and percent of subjects; Some questions the total number does not meet the actual because some women did not answer (don't know). $*_{\mathrm{p}}<0.05$ was considered significant 
Table 2: Comparison between both groups' information sources (Q13 answers)

\begin{tabular}{llll}
\hline Information source & \multicolumn{2}{l}{ Number of subjects (\%) } & $\mathbf{p}$ \\
\cline { 2 - 3 } & $\begin{array}{l}\mathbf{1 8 - 4 5} \text { years } \\
\mathbf{( n = 1 0 7 )}\end{array}$ & $\begin{array}{l}\mathbf{> 4 5} \text { years } \\
\mathbf{( n = 1 0 6 )}\end{array}$ \\
\hline Personal experience & $51(47.6)$ & $87(82)$ & $0.0001^{*}$ \\
Pharmacist education & $11(10.2)$ & $27(25.4)$ & $0.0037^{*}$ \\
physician education & $27(25.2)$ & $33(31.1)$ & 0.338 \\
Internet & $45(42)$ & $32(30.1)$ & 0.071 \\
Television & $29(27.1)$ & $56(52.8)$ & $0.0001^{*}$ \\
Radio & $8(7.4)$ & $12(11.3)$ & 0.336 \\
Ministry of health activities & $35(32.7)$ & $48(45.2)$ & 0.059 \\
\hline
\end{tabular}

${ }^{*} \mathrm{p}<0.05$ was considered significant. Many subjects have more than one source of information

many efforts are needed to help elderly to get benefit from this source to obtain e-health services and since the development of information and communications technology tools increasingly meets the evolving requirements of patients in the area of e-health. More elderly become beneficiaries of such services $[10,11]$

The effect of medical professionals (pharmacists) as a source of health information was more prominent in the older group than in the younger one, this reflects the importance of this sector in providing health knowledge, this result agrees with a study done in Palestine found that community pharmacists' role is a major part to make a potential impact in ensuring that medicines are used correctly [12]. In addition to that, In India Umira et al. in 2015 found that using special devices, pictograms, and charts may help to increase health literacy especially in rural areas [13].

A study conducted in Indonesia by Asmini in 2017 concluded that patient education of drug information could improve patients' knowledge by $100 \%$ and achieve a therapeutic outcome [14].

In the current study, radio was the least source of information for both groups.

\section{CONCLUSION}

Young women had a good knowledge on common medical problems, but the old showed overall limited health knowledge. Personal experience and TV were the main sources of information for the older group while personal experience followed by internet for younger women. Pharmacists' contact is very impotent in health literacy in the older group.

Recommendation: It is important to use TV effectively to improve the level of knowledge in the general population, especially the older women. More oriented use of the internet will completely improve the health education, especially in young women.

\section{REFERENCES}

1. Available from: http://www.who.int/topics/health_education/en. [Last cited on $2017 \mathrm{Feb}$ 14]

2. Asaolu SO, Ofoezie IE. The role of health education and sanitation in the control of helminth infections. Acta Trop 2003;86:283-94.

3. Benjamin RM. Improving health by improving health literacy. Public Health Rep 2010;125:784-5.

4. Lambert M, Luke J, Downey B, Crengle S, Kelaher M, Reid S, et al. Health literacy: Health professionals' understandings and their perceptions of barriers that indigenous patients encounter. BMC Health Serv Res 2014;14:614.

5. Nutbeam D. Health literacy as a public health goal: A challenge for contemporary health education and communication strategies into the $21^{\text {st }}$ century. Health Promot Int 2000;15:259-67.

6. Brata C, Gudka S, Schneider CR, Clifford RM. A review of the provision of appropriate advice by pharmacy staff for self-medication in developing countries. Res Social Adm Pharm 2015;11:136-53.

7. Wiesner M, Pfeifer D. Building a widespread public health education system for developing countries in Africa. Stud Health Technol Inform 2013;190:240-2.

8. Barah F, Gonçalves V. Antibiotic use and knowledge in the community in Kalamoon, Syrian Arab republic: A cross-sectional study. East Mediterr Health J 2010;16:516-21.

9. Smith-Barbaro PA, Licciardone JC, Clarke HF, Coleridge ST. Factors associated with intended use of a web site among family practice patients. J Med Internet Res 2001;3:E17.

10. Bujnowska-Fedak MM, Mastalerz-Migas A. Usage of medical internet and e-health services by the elderly. Adv Exp Med Biol 2015;834:75-80.

11. Connell CM, Crawford CO. How people obtain their health information. A survey in two Pennsylvania counties. Public Health Rep 1988;103:189-95.

12. Al-Ramahi R. Patterns and attitudes of self-medication practices and possible role of community pharmacists in Palestine. Int J Clin Pharmacol Ther 2013;51:562-7.

13. Umira SA, Mallesh M, Divyaja M, Sree D. Assessment of patient's knowledge regarding dispensed medication in a South Indian government hospital. Int J Pharm Pharm Sci 2015;7:544-7.

14. Asmini P. The influence of education of drug information by pharmacist on the improvement of knowledge and therapeutic target to Type 2 diabetes mellitus outpatients in hospital. Int J Pharm Pharm Sci 2017;9:199-204 